\title{
Modified Convergent Flow Tracing Method for Evaluating Advective Velocity and Effective Porosity in Fractured Rock Aquifers
}

\author{
Byung-Woo Kim ${ }^{1}$ and Hangbok Lee ${ }^{2, *}$ \\ 1 K-water Research Institute, Korea Water Resources Corporation, Daejeon 34045, Korea; bwkim@kwater.or.kr \\ 2 Center for Deep Subsurface Research, Korea Institute of Geoscience and Mineral Resources, \\ Daejeon 34132, Korea \\ * Correspondence: leehb@kigam.re.kr; Tel.: +82-42-868-3844
}

Received: 11 November 2020; Accepted: 15 December 2020; Published: 18 December 2020

\begin{abstract}
This study presented the analysis of the modified convergent flow tracing method, which is a modified virtual solute transport approach to retrieve tracer masses from a pulse image (virtual) well to an extraction well. In the convergent flow tracer test, approximate analytical solutions were extended for the pulse image well using a single-well tracing method. This method transformed the drift-and-pumpback conditions of the single-well tracing method. The method requires a prior information of the effective porosity. Using sodium chloride as a tracer mass, the tracer data sampled through field-scale tests were used to obtain breakthrough curves. This modified method was different from the pre-existing single method because it considers both the ambient groundwater movement (the two classes of drifts) and the constant volumetric flow rate during the pumping phase. The method was applied to the tracer test at underground research tunnel for verifying the theory inductively derived from the single tracing method. Through field tests, the values of velocity and porosity were compared to the results of the drift-and-pumpback equations of the single-well test, and the several different equations related to breakthrough curves of the two-well tests conducted on a field scale.
\end{abstract}

Keywords: modified convergent flow tracing method; solute transport; convergent flow tracer test; effective porosity; drift-and-pumpback equations

\section{Introduction}

Accurate estimates of the advective velocity (AV) and effective porosity (EP) are crucial for understanding the parameters that control solute transport in aquifers and movement of radioactive wastes [1,2]. In particular, advection and dispersion in aquifers govern solute transport. Advection is a solute transport process governed by the $\mathrm{AV}$ of water in which the tracer mass is dissolved, whereas dispersion is the movement of the tracer mass during the flow of a tracer plume. Dispersion is directly related to the second moment of a breakthrough curve and is usually considered a tensor quantity in the field, whereas EP is a scalar quantity that is effectively the ratio of the specific discharge to AV.

Typically, Darcy's equation (1856) [3], "Q $=$ KIA", includes a linear velocity term written as " $\mathrm{v}_{\mathrm{a}}=\mathrm{KI} / \mathrm{n}_{\mathrm{e}}$," or $\mathrm{EP}$, " $\mathrm{n}_{\mathrm{e}}=\mathrm{KI} / \mathrm{v}$," where $\mathrm{Q}$ is the flow rate, $\mathrm{K}$ is the hydraulic conductivity, $\mathrm{I}$ is the hydraulic gradient, and A is the cross-sectional area. In aquifers, where both Darcy's equation and the velocity equation (with the consideration of the effects of the regional velocity during the tracer tests) are valid. The two equations can be substituted, one on the other, and rearranged to yield algebraic expressions for velocity and porosity. In particular, Leap and Kaplan (1988) [4] reported that the single-well drift-and-pumpback tracer test is useful for estimating the groundwater velocity. 
Hall et al. (1991) [5] suggested an equation using the drift-and-pumpback tracer test for determining two independent functional relationships between AV and EP. Stephens et al. (1998) [6] compared estimates of EP derived from soil-water characteristic curves and particle size, and those obtained from laboratory or field tracer tests. Although they estimated AV using the equation of Leap and Kaplan (1988), the reliabilities of the two parameters were not evaluated, particularly at fractured rock aquifers. Fernàndez-Garcia et al. (2002) [7] suggested EP to be assumed as the geometric mean of the principal components of the apparent porosity tensor in order to obtain a meaningful EP value estimated from radial flow tracer tests. Neuman (2005) [8] suggested that EP, a quantity relating AV to the Darcy flux, may show directional variations in field tracer tests. The difference between the $\mathrm{AV}$ of a conservative solute and the Darcy flux may indicate that the hydraulic properties and mass transport process are far more complex and sophisticated than are typically understood. Moreover, the measurement of an accurate $\mathrm{AV}$, as opposed to that of the Darcy flux, is a crucial factor in the predictive evaluation method of a waste disposal site in terms of safety in the storage of the waste pollutants.

Therefore, the main objective of this study is the field verification of a two-well tracer test method in which a pulse tracer is emplaced in an injection well and allowed to drift with the groundwater movement (two classes of drift) from the injection well (or pulse image well) to the extraction well, and then allowed to drift at a constant volumetric flow rate during pumping in the extraction well. In Darcy's law and the equation for the drift and volumetric flow rate during pumping, a modified method can be substituted and rearranged to yield algebraic expressions for AV and EP in two nonlinear simultaneous equations having two unknowns. In this approach, it was attempted to estimate AV and EP through the modified method, in which a pulse injection of the tracer mass was injected into six wells (SP-02, 03, 04, 06, 08, and 10) among a total of ten test wells, and then extracted out only from well SP-5 in all two-well tracer tests. The results of the modified method were compared with those of the single-well test (SP-05 well) using the drift-and-pumpback equation.

\section{Field Study}

\subsection{Field Site}

As depicted in Figure 1, the test boreholes are all located in the underground research tunnel, built in a mountainous area at the site of Daejeon, Korea. Study tunnel has a total length of $255 \mathrm{~m}$ with a $180 \mathrm{~m}$ long access tunnel and two research modules with a total length of $75 \mathrm{~m}$ (research right and left modules have lengths of 45 and $30 \mathrm{~m}$, respectively). The maximum depth of the tunnel is $90-100 \mathrm{~m}$ from the top of a mountain located above the site. A downward main tunnel slope with a 10\% gradient was built to achieve the required minimum depth for the underground research laboratory. This study area is mainly composed of Precambrian gneiss, Mesozoic plutonic rocks, and dyke rocks [9]. Mesozoic plutonic rocks can be largely divided into schist granite and Mesozoic two-mica granite. Among these, two-mica granite is the most widely distributed rock over the entire study area, and it intrudes the Jurassic gneiss granite. This two-mica granite is neutral to fine-grained, and the main constituent minerals are quartz, plagioclase, anorthoclase, biotite, muscovite mica, and a small amount of zircon, rutile and apatite are observed [10]. According to the drilling core analysis, the chlorosis of biotite is frequently observed regardless of the depth of the core. Considering that ore minerals such as pyrite and molybdenite are produced in the section in which some quartz veins are produced, it is considered that local mineralization has occurred [10]. 


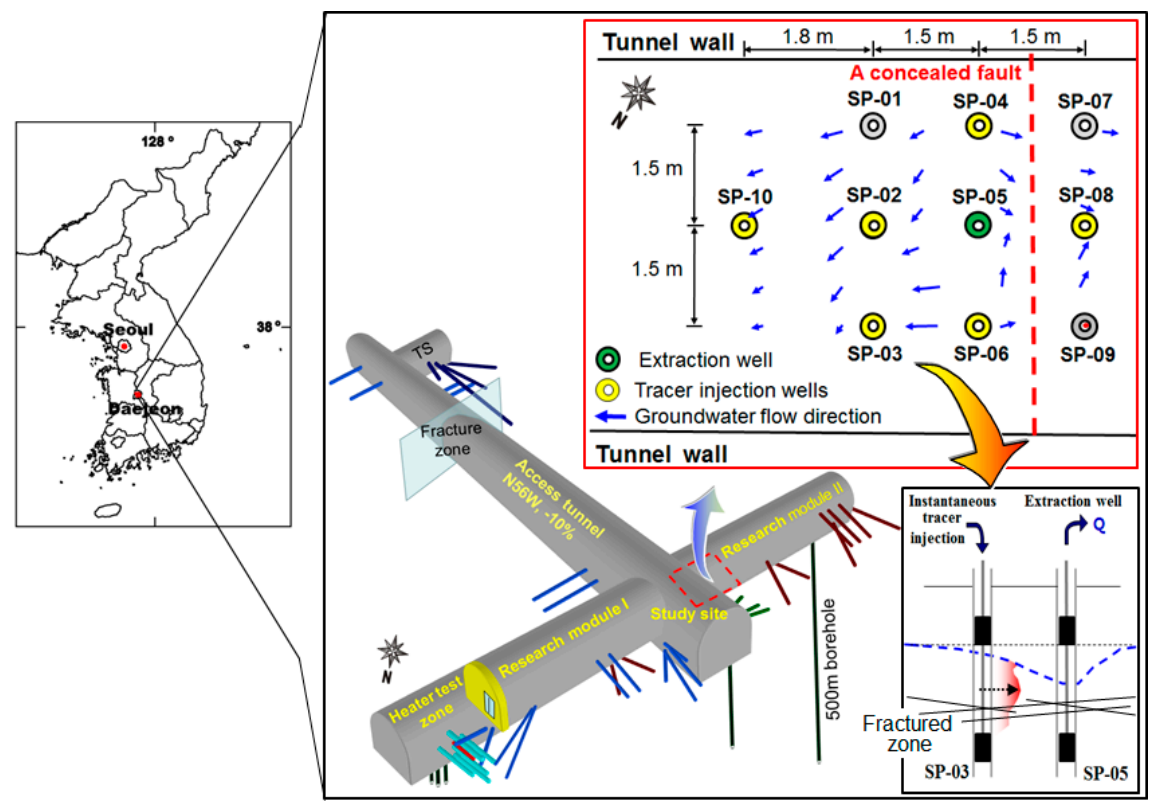

Figure 1. Tracer well location, groundwater flow direction, and zonal convergent flow tracer test using double packers in study area.

The layout of study tunnel is shown in Figure 1, where it can be noted that 10-m shallow boreholes were drilled without screen section. The surface soil over the fractured rock is covered with granular sediments, which extend from the tunnel floor to a depth of $0.2-0.3 \mathrm{~m}$. The picture in the red rectangular box is a top view from above, which represents underground ten boreholes drilled vertically from the tunnel floor. All ten test boreholes with depth of $10 \mathrm{~m}$ were denoted as "SP" and numbered 1 to 10 in order. They were used to investigate the hydrological characteristics and field applicability of the deep borehole system. A convergent flow tracer test (CFTT) was conducted at a test site in the granite confined aquifers of study tunnel. The separation distance between the extraction well (SP-05) and injection wells was from 1.5 to $3.3 \mathrm{~m}$, and well diameters were $0.076 \mathrm{~m}$ at a depth $0.3-10 \mathrm{~m}$ below the top of the casing. All ten test boreholes with depth of $10 \mathrm{~m}$ were the artesian wells and their static water level were within $0.3-0.5 \mathrm{~m}$ above the tunnel floor. The ambient heads were evaluated by measuring the height of the water column by connecting a transparent acrylic tube upward based on the tunnel floor of each borehole. Although a slight difference in ambient head between each borehole induced a regional anisotropic flow as shown in Figure 1, the difference degree was very small (from 0.3 to $0.5 \mathrm{~m}$ ) and it corresponds to a relatively low natural head gradient. Unlike the natural gradient tracer test, this weak flow of natural groundwater may not significantly affect the forced gradient tracer test using injection-extraction method in this study.

\subsection{Hydraulic Characteristics}

The hydraulic characteristic is a constant of proportionality that describes the permeability of the media and physical properties of fluid flow through a fractured mass. The test wells had a fractured zone of high permeability in the section between the depths of groundwater level (GL) -5.03 and $-7.93 \mathrm{~m}$ below the tunnel floor. Geophysical logging, full penetration and zonal pumping tests, and a constant pressure injection obtained from 10 wells were analyzed to determine suitable intervals for the zonal tracer test (aquifer thickness). A schematic of the experimental set up using the straddle double packer is shown in Figure 2. The double packers were installed at intervals of $1.12 \mathrm{~m}$ where the fractured zone passed through all boreholes. They were continuously positioned in the target section even during the total tracer tests. A constant pumping rate range of $1.17 \times 10^{-5}-1.18 \times 10^{-5} \mathrm{~m}^{3} / \mathrm{s}$ was employed at the extraction well (SP-05) for approximately $8 \mathrm{~h}$. The hydraulic conductivity was calculated using the equation for slab-shaped blocks, as reported by Barker (1988) [11]. Table 1 summarizes the hydraulic 
parameters of the zonal pumping tests. $\mathrm{Q}$ is the pumping rate, $\mathrm{K}$ is the hydraulic conductivity, $\mathrm{b}$ is the thickness of test section and I is the hydraulic gradient.

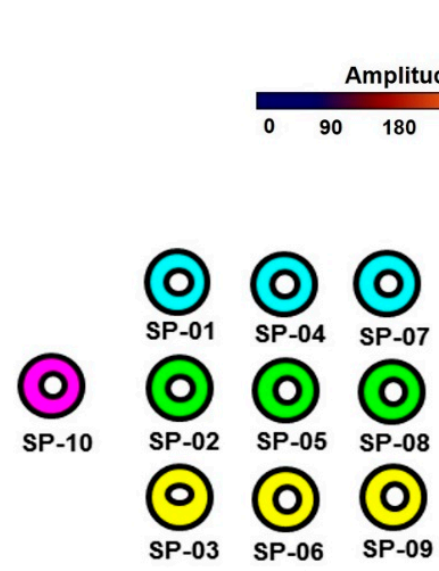

Test well location

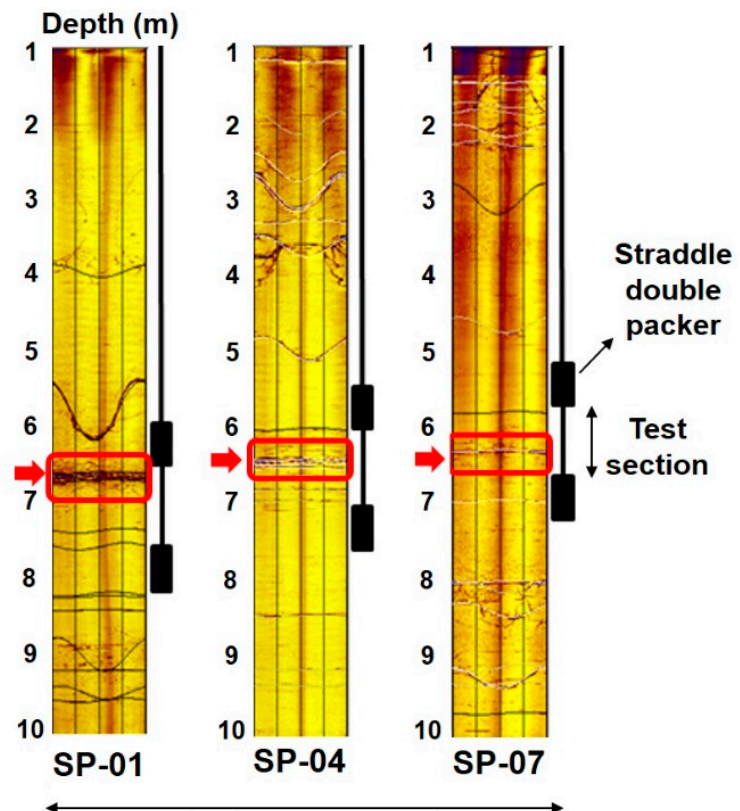

Horizontal axis 1

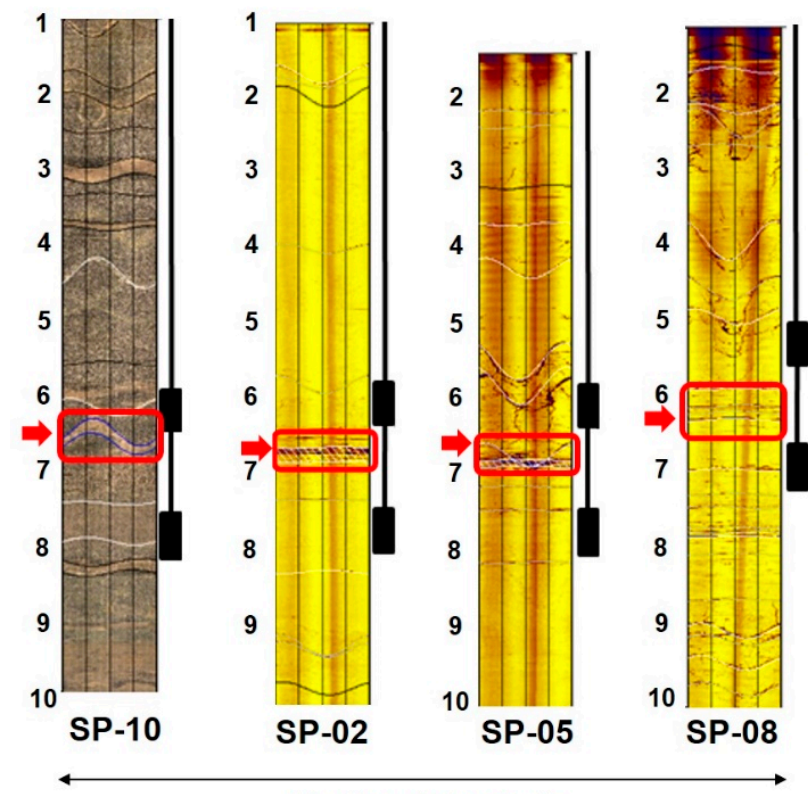

Horizontal axis 2
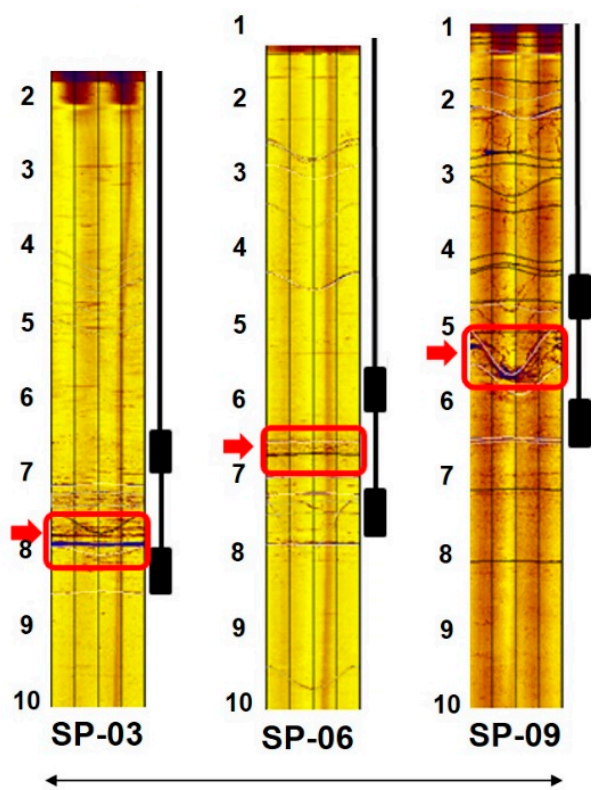

Horizontal axis 3

Figure 2. Schematic of the location of double packer and fracture distribution in mainly fractured zone.

Table 1. Results of hydraulic parameters using zonal pumping test.

\begin{tabular}{lcccccc}
\hline Well ID & Separation Distance $(\mathbf{m})$ & $\mathbf{Q}\left(\mathbf{m}^{3} / \mathbf{s}\right)$ & $\mathbf{K}(\mathbf{m} / \mathbf{s})$ & $\mathbf{b}(\mathbf{m})$ & $\mathbf{I}$ & Note \\
\hline 02 to 05 & 1.50 & $1.18 \times 10^{-5}$ & $2.17 \times 10^{-6}$ & 1.12 & 0.31 & Two-well test \\
03 to 05 & 2.21 & $1.18 \times 10^{-5}$ & $2.27 \times 10^{-6}$ & 1.12 & 0.28 & Two-well test \\
04 to 05 & 1.50 & $1.18 \times 10^{-5}$ & $3.38 \times 10^{-6}$ & 1.12 & 0.28 & Two-well test \\
05 to 05 & 0 & $1.18 \times 10^{-5}$ & $2.17 \times 10^{-6}$ & 1.12 & 0.14 & Single well test \\
06 to 05 & 1.50 & $1.17 \times 10^{-5}$ & $3.08 \times 10^{-6}$ & 1.12 & 0.30 & Two-well test \\
08 to 05 & 1.50 & $1.18 \times 10^{-5}$ & $3.67 \times 10^{-6}$ & 1.12 & 0.31 & Two-well test \\
10 to 05 & 3.33 & $1.18 \times 10^{-5}$ & $2.24 \times 10^{-6}$ & 1.12 & 0.16 & Two-well test \\
\hline
\end{tabular}


Since it was necessary to perform a zonal tracer test through a target section with high permeable connectivity, the hydraulic tests (pumping tests and constant pressure injection test) performed to obtain the hydraulic characteristics were conducted only in a limited section. Therefore, these zonal hydraulic parameters do not represent the hydraulic characteristics of the entire rock aquifer in the study area.

\subsection{Aquifer Characteristics}

The aquifer is connected by the same flow path throughout, and is considered to be horizontally homogeneous, having a fractured zone. The aquifer referred to in this study means a space with a total thickness of $10 \mathrm{~m}$ of a fractured rock that is penetrated by all test boreholes. A $1.12 \mathrm{~m}$ thick zone represents the target section in the study aquifer where the actual tracer test is performed.

The effects of the fracture (both impermeable and permeable fractures, and only permeable fracture) and the required distributions of fluid and solute transport have been evaluated based on fracture densities. In this study, the permeable possibility of rock fractures was classified on the basis of the amplitude and scan image data of the fractures identified by ultrasonic scanning logging. The amplitude image suggests information on the relative rock strength as well as the developmental state of fractures and faults, and the scan image represents the function of data correction or high-resolution pore path detection. Since the televiewer scan image becomes the basic data that can obtain the distance from the center of the borehole cross section to the wall, the internal shape of the borehole can be expressed with high resolution. This potentially provides information about whether the fractures are filled with a filling material or are open. A permeable fracture means a fully open joint or a semi-open joint through which groundwater can flow, and an impermeable fracture means a joint that does not actually cause groundwater flow because it is completely closed or the aperture is filled with a filling material. However, there is still no absolute criterion (arbitrary cutoff) for accurately classifying the permeability of fractures, and it may vary slightly depending on the performance and resolution of the logging equipment and the analysis method. Therefore, the permeability of the fractures that were first classified through image logging, which was hydraulically verified once more through the zonal pumping test and constant pressure injection test in this study.

The spatial distribution of permeability is mainly dependent on the sum of the number of permeable fractures penetrating through target section, because the groundwater in rock aquifer flows only through the permeable fracture, not the closed fractures or matrix. Based on the physical logging results (BHTV and BIPs) of ten test boreholes, the individual fracture density was calculated at an interval of $1.12 \mathrm{~m}$ in the zonal tracer test. The unit $1 / \mathrm{m}$ for the fracture density means the total number of rock fractures per unit length of target section. The results are summarized in Table 2.

Table 2. Results of fracture and hydraulic fracture densities in zoning tracer tests (unit: $\mathrm{m}^{-1}$ ).

\begin{tabular}{|c|c|c|c|c|c|}
\hline Well ID & Fractures ${ }^{(1)}$ & Permeability Fractures & Well ID & Fractures ${ }^{(1)}$ & Permeability Fractures \\
\hline SP-01 & 2.68 & 0.89 & SP-06 & 5.36 & 2.68 \\
\hline SP-02 & 4.46 & 4.46 & SP-07 & 4.46 & 1.79 \\
\hline SP-03 & 2.68 & 1.79 & SP-08 & 4.46 & 1.79 \\
\hline SP-04 & 2.68 & 1.79 & SP-09 & 3.57 & 1.79 \\
\hline SP-05 & 4.46 & 4.46 & SP-10 & 7.14 & 5.36 \\
\hline
\end{tabular}

(Remark) $^{(1)}$ is sum of impermeability and permeability fractures.

In addition, the fracture densities are analyzed to characterize the tracer responses in the intervals of the zonal tracer tests, including a highly complex structure of fracture. The fracture densities were illustrated with 3D distribution maps. Only the fractures (the total of impermeability and permeability fractures) and densities of the permeability fractures are shown in Figures 3 and 4, respectively. 


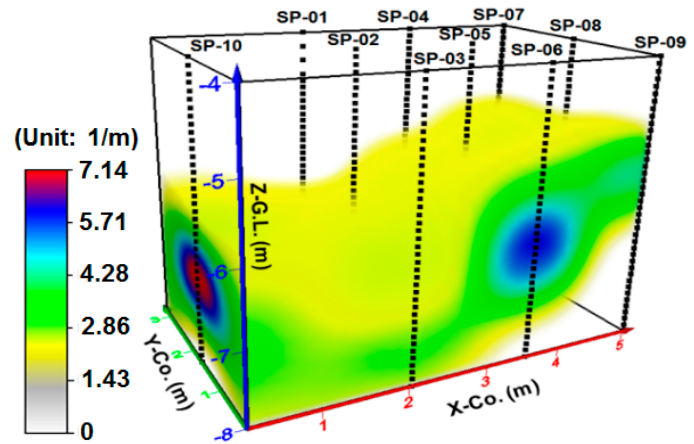

(a)

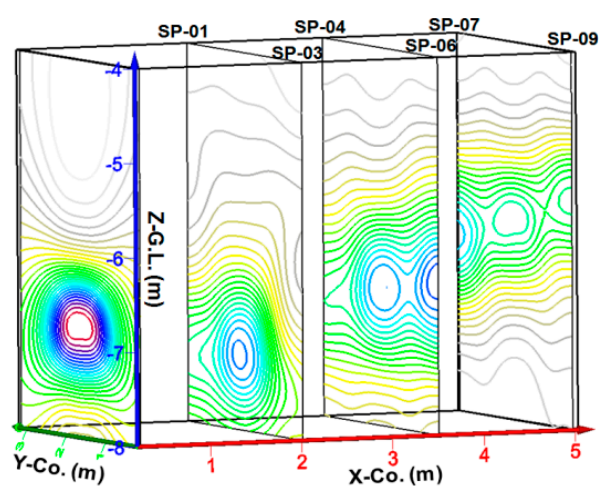

(c)

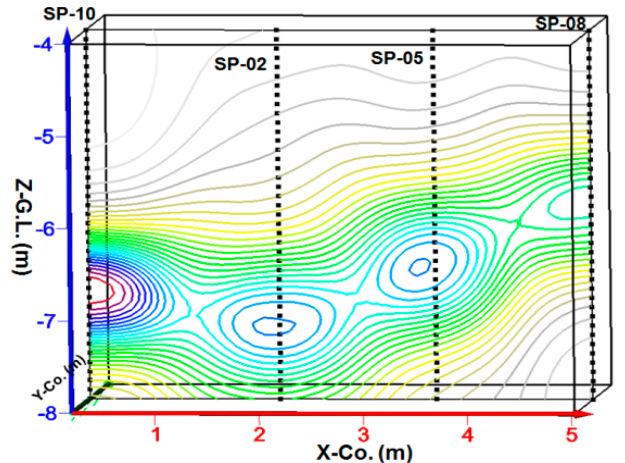

(b)

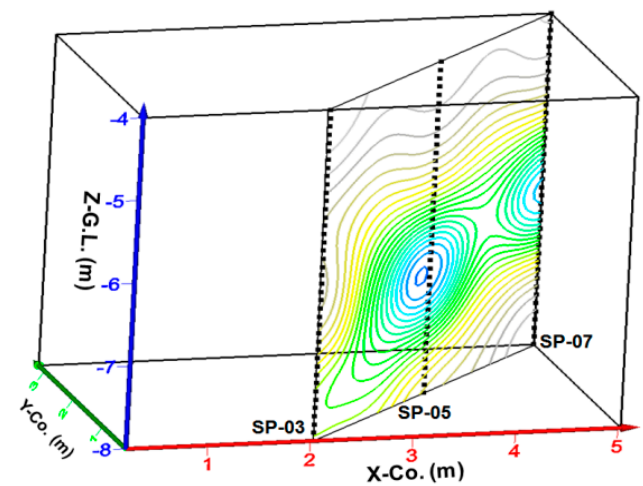

(d)

Figure 3. Analysis of the fracture densities at intervals of $1.12 \mathrm{~m}((\mathbf{a}) 3 \mathrm{D}$ spatial distribution; (b) section view of SP-10, 02, 05, and 08 wells; (c) section view from SP-01 to 03 wells, 04 to 06, and 07 to 09 wells; and (d) section view of SP-03, 05, and 07 wells).

As depicted in Figure 3, the spatial distribution of the fractures appeared to be complete structural interconnections because of the existence of a number of large fractures. The spatial distribution of permeable fractures as depicted in Figure 4 shows the hydraulic interconnection between the permeable rock fractures in the test boreholes. The fracture network did not interrupt the movement of the tracer particles. Therefore, the main flow paths of the tracers from the injection to the extraction wells were directly connected with SP-10, 02, and 05 wells, as shown in Figure 4b. On the other hand, the rest of the wells, exclusive of SP-10, 02, and 05 wells (located in a horizontal line), appear to be low in interconnection between the permeable parts of the fractures in the wells, as shown in Figure 4c,d. Especially, the red dotted line shown in Figure 1 represents a concealed vertical fault, which acts as a barrier that separates (cut off) the groundwater flow on the left and right. As can be seen in Figure 4, the boreholes (SP-01, 02, 03, 04, 05, 06, 10) on left side of the fault were well-connected through horizontal permeable fractures, but the right-side boreholes (SP-07, 08, 09) did not have the spatial distribution of the permeable fractures penetrating together. 


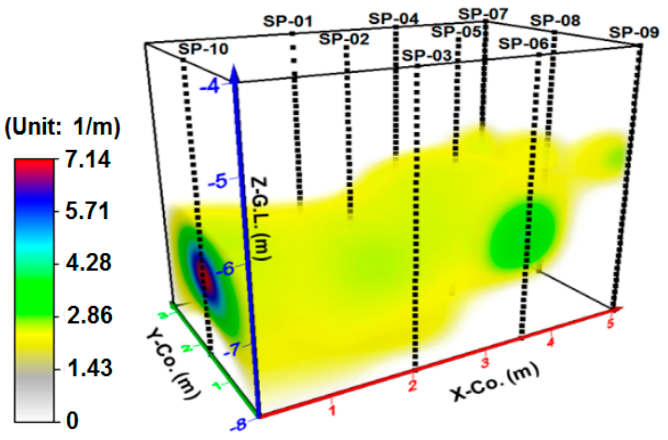

(a)

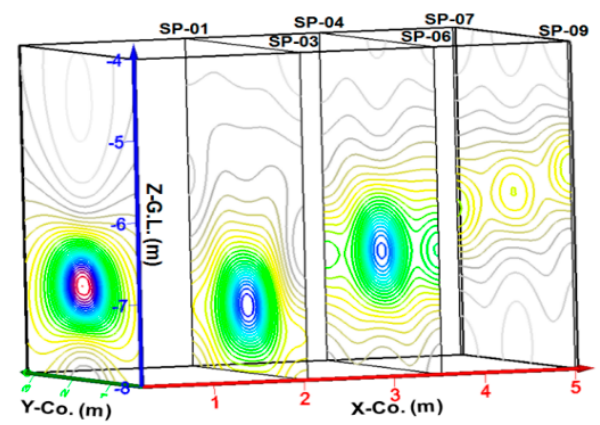

(c)

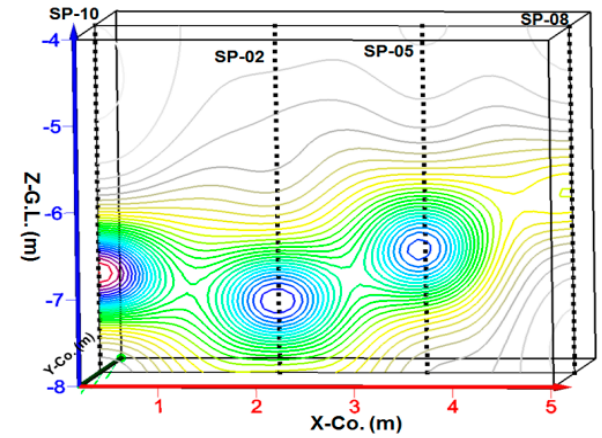

(b)

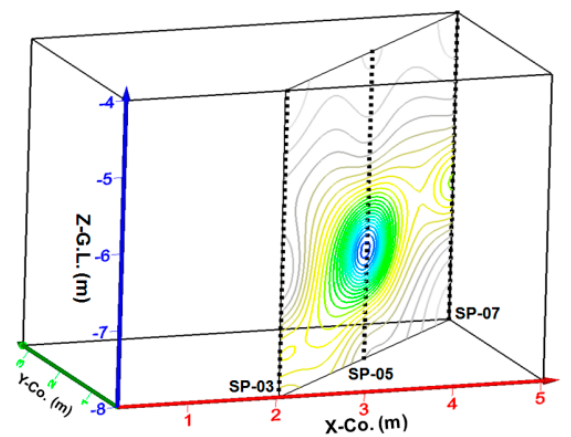

(d)

Figure 4. Analysis of the permeability fracture densities at intervals of $1.12 \mathrm{~m} \mathrm{((a)} \mathrm{3D} \mathrm{spatial} \mathrm{distribution;}$ (b) section view of SP-10, 02, 05, and 08; (c) section view from SP-01 to 03, 04 to 06, and 07 to 09 wells; and (d) section view of SP-03, 05, and 07 wells).

Consequently, the estimated densities in the fractures and permeability fracture models were then used to predict the movement of tracer particles. The fracture densities can be used to predict the dispersive structure by comparing the fractures and permeable fracture densities with breakthrough curve (including the curve type of prolonged tailing).

\section{Theory and Experiment}

\subsection{Overview}

At the study site, two solute transport processes (Figure 5a), governing the solute transport in groundwater, can be distinguished, specifically, advection, and dispersion/diffusion. In particular, dispersion and density/viscosity differences in an equilibrium transport may accelerate tracer mass movement, whereas incomplete mixing processes in a non-equilibrium transport can slow the rate of movement. Liu and Kitanidis (2012) [12] suggested that dispersivity in the porous media can reduce the rapid fluid velocity in non-equilibrium problems, because the main mass transfer mechanism is mixing instead of dispersion. Hauns et al. (2001) [13], and Becker and Shapiro (2000) [14], attributed different shapes of breakthrough curves for fractured rock to a given type of dispersive structure and diffusive rock matrix, as depicted in Figure $5 b$. 


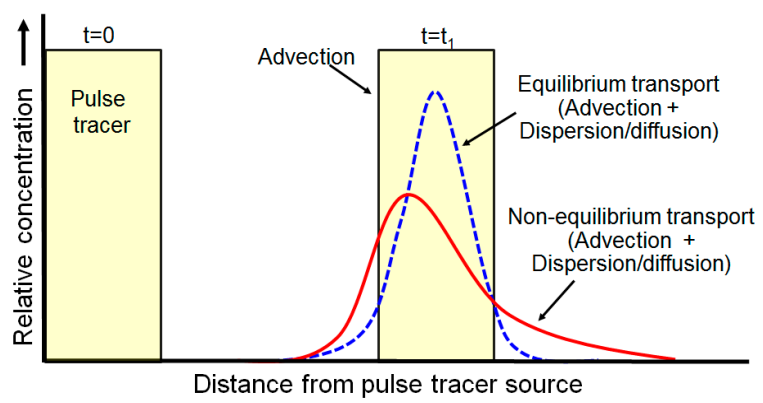

(a)

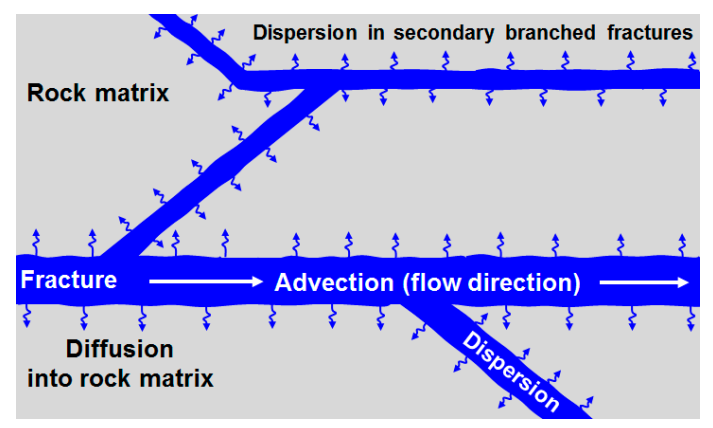

(b)

Figure 5. Transport processes because of (a) pulse tracer injection in groundwater and (b) fractured rock mass.

In general, the flow paths of tracers are affected by the presence of numerous fractures. The distribution of permeability, as depicted in Figure 6, is governed by the sum of the products from each fracture passing between injection and extraction wells [15]. Thus, the permeability distributions because of the high fracture density appear to be heterogeneous, depending on the number of existing large fractures. On the other hand, the presence of a number of large fractures, as depicted in Figure 6a, is assumed to provide a relatively very permeable fluid medium. However, the tracer particles do not move in a straight line along the direction of the extraction well, as shown in Figure $6 \mathrm{~b}, \mathrm{c}$. The presence of fast preferential flow paths is because of the heterogeneous arrangement of fractures, and the tailing tracer breakthrough curve indicated a non-equilibrium transport. The retardation related to dispersive structures can cause the rising hinge of the peak to merge with the dispersed part and lead to a falling hinge. As shown in Figure $6 b, c$, the advection in a non-equilibrium transport can be described by an axisymmetric curve from the first to the peak arrival concentrations. Hence, the peak concentration was associated with the plume's centroid, which was used as a parameter in order to estimate AV and EP in the fractured rock mass. In addition to the effects of the joint density discussed above, the length, aperture geometry, orientation and connectivity of rock fractures are very important elements of fracture network. Quantitative analysis of these factors through laboratory experiments, modelling, and field tests is essential to determine the effect of the fracture network on the solute transport represented by the breakthrough curve. 

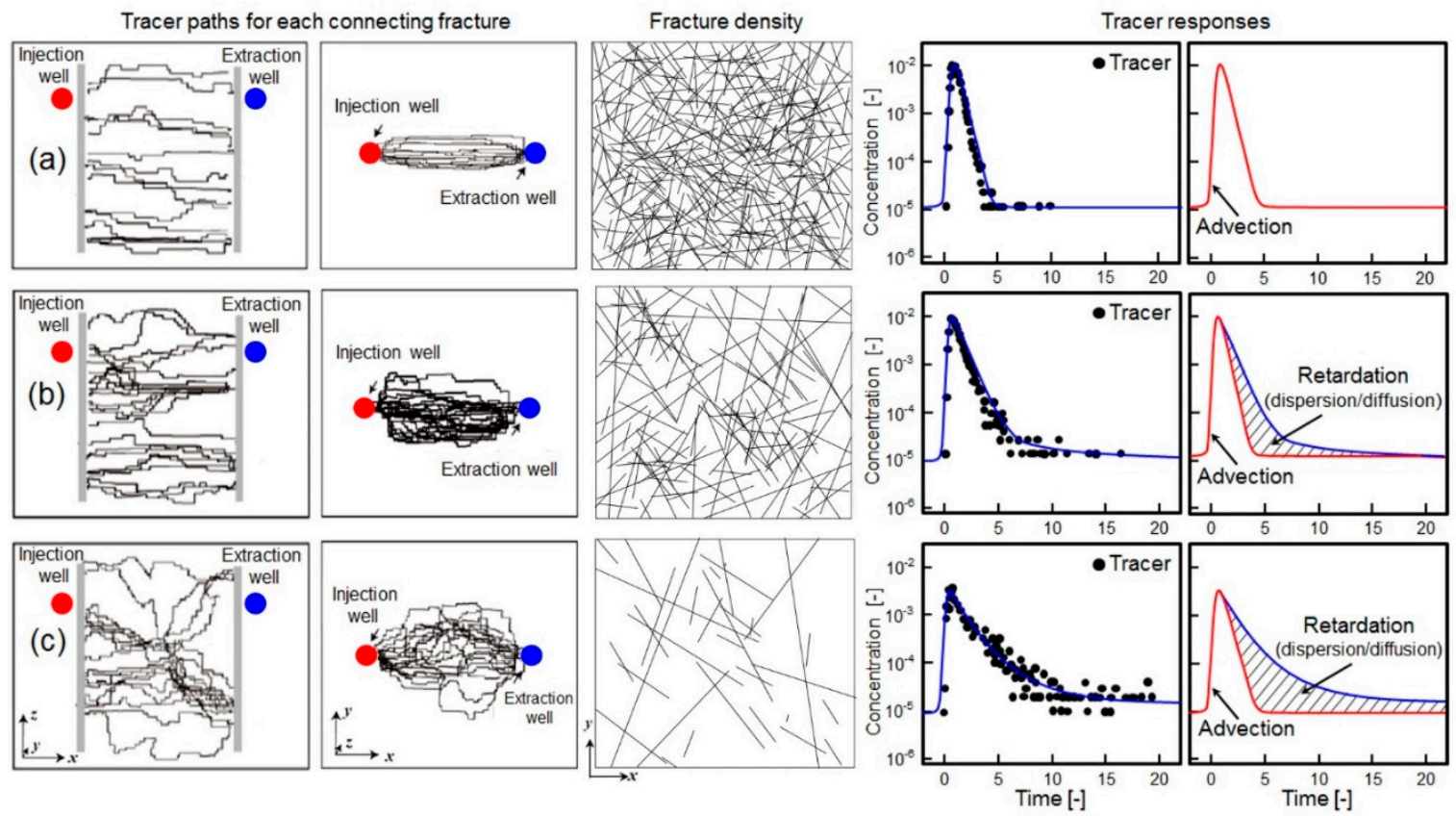

Figure 6. Tracer pathways and tracer responses of breakthrough curves according to the fracture density of (a) high, (b) moderate and (c) low values (injection well—red circle, extraction well—blue circle), which was modified from Suzuki et al. (2012) [15].

\subsection{Modified Method}

The concentration in the extraction well is equal to the average concentration in the aquifer around the well. According to Zlotnik and Logan (1996) [16], the equation for tracer concentration in the extraction well can be expressed to a single boundary condition as Equation (1):

$$
\pi r_{w}^{2} b_{e} \frac{\partial C}{\partial t}=2 \pi r_{w} b n_{e} D_{r} \frac{\partial C}{\partial r}, r=r_{w}
$$

where $C$ is the tracer concentration, $r$ is the distance between two wells, $r_{w}$ is the radius of the well, $n_{e}$ is the effective porosity, and $D_{r}$ is the coefficient of longitudinal (radial) dispersion, which is determined by the longitudinal dispersivity, $\alpha_{L}$ and $\alpha_{L}|V|$. However, it is assumed that the initial and boundary conditions of the extraction well can be expressed as Equation (2):

$$
\begin{gathered}
t=0 \text { or } C=0 \\
r=0 \text { or } C=C_{\text {injection }}(t) \\
r=0 \text { or } \frac{\partial C}{\partial r}=0 \\
r=\infty \text { or } C=0 \\
z=0 \text { or } \frac{\partial C}{\partial z}=0 \\
C(r, 0)=0
\end{gathered}
$$

To illustrate this, the velocity at any point along the tracer path during the constant-rate pumping $(Q)$ can be expressed by superposing the velocity because of the extraction $\left(v_{e}\right)$. An element volume, $v_{e}$, was calculated as the volume of a cylindrical element corresponding to the ideal radial flow and constant average thickness was assumed [17].

$$
v_{e}(r)=-\left(Q t / \pi b n_{e}\right)^{1 / 2}
$$


The breakthrough curve of the two-well tracing test was applied, in which a pulse tracer was placed and allowed to drift for the first and peak concentration arrivals between the two wells at a constant volumetric flow rate because of constant pumping, as shown in Figure 7a. As shown in Figure 7b, a pulse, which began drifting at time $t_{i}$, was applied and continued along the hydraulic gradient direction, $r$, at the flow velocity until time $t_{f}$, when a short pulse injection of tracer encountered the first concentration arrival of the mass at the extraction well. Therefore, $r_{1}$ he true radial displacement, is the first drift for the travel range between the two wells. As illustrated in Figure 7c, we used the tracer image well theory, from which the influence of the pulse position boundaries on the two-well tracing test can be determined. The tracer image well theory assumes that the pulse position is a hypothetical well, which simulates the injection of the pulse tracer located in the hydraulic boundary in the nearby injection well. The apparent radial displacement, $r_{2}$, is the second drift for the travel range between times $t_{i}$ and $t_{p}$ of the regional flow, away from the image well toward the extraction well. Because of the steady-state flow as a result of constant pumping, it is as though a short pulse injection of tracer were injected into the tracer's image well, where the hydraulic boundary is located. The true radial displacement, $r_{3}$, is the travel range between times $t_{i}$ and $t_{p}$, as a result of the constant volumetric flow rate toward the extraction well.

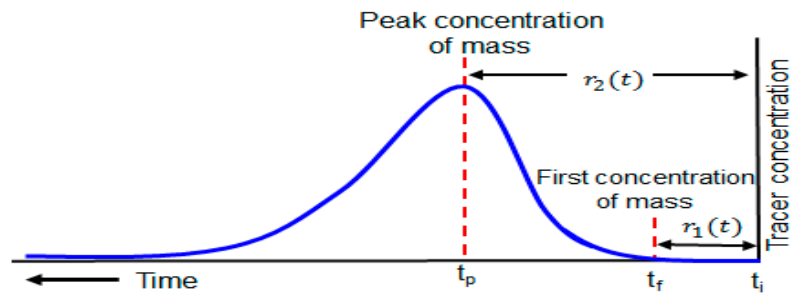

(a)

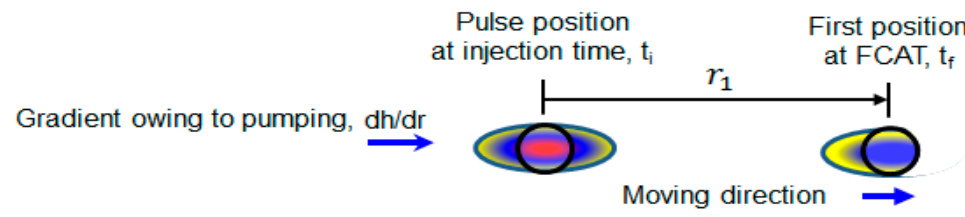

(b)

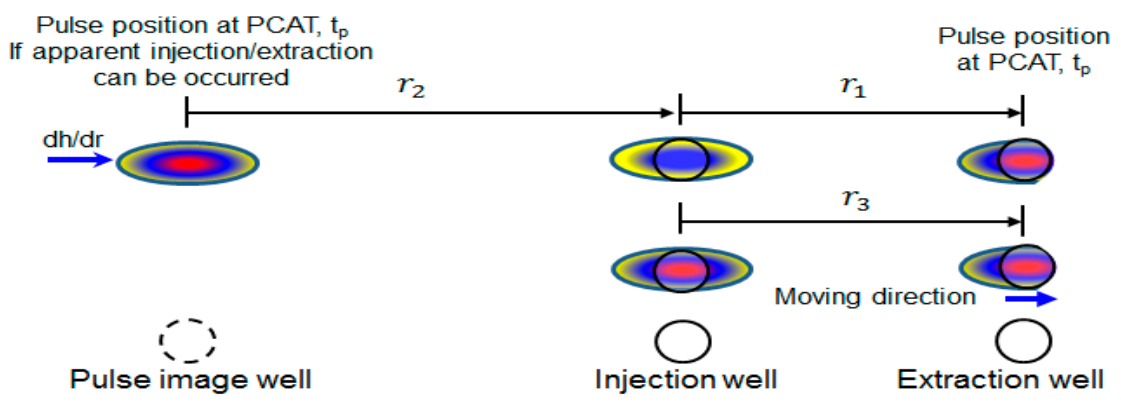

(c)

Figure 7. Schematic of tracer pulse history in convergent flow tracer test: (a) typical breakthrough curve owing to two-well tracing test, (b) during pulse pumping in an extraction well, pulse position of first concentration arrival is pulse drift between two wells, and (c) pulse history including first drift (from injection to first concentration arrival time (FCAT)), second drift (from injection to PCAT), and apparent radial position; $r_{1}$ and $r_{2}$ are radial displacements owing to the steady-state flow of constant pumping, and $r_{3}$ is the true radial displacement owing to constant volumetric flow rate of constant pumping in extraction well (where, $r_{1}$ or 3 is a true radial position). 
The AV of the true/apparent radial positions can be written from Equation (4) as Equation (5). It was attempted to invoke the principle of superposition to obtain the following equations for the radial position of the tracer from the well as a function of time.

$$
\begin{gathered}
r(t)=r_{1}(t)+r_{2}(t)+r_{3}(t) \\
d r / d t=\left(d r_{1} / d t\right)+\left(d r_{2} / d t\right)+\left(d r_{3} / d t\right) \\
\int_{0}^{r_{1}} d r_{1}=v_{a} \int_{t_{i}}^{t_{f}} d t, \int_{r_{1}}^{r_{2}} d r_{2}=v_{a} \int_{t_{i}}^{t_{p}} d t, \text { and } 2 \int_{r_{1}}^{0} d r_{3}=\left(Q / \pi n_{e} b\right) \int_{t_{i}}^{t_{p}} d t \\
r_{1}=v_{a}\left(t_{f}-t_{i}\right), r_{2}=v_{a}\left(t_{p}-t_{i}\right), \text { and } r_{3}=-\left(Q / \pi n_{e} b\right)^{1 / 2}\left(t_{p}-t_{i}\right)^{1 / 2}
\end{gathered}
$$

Therefore, Equation (8) below can be expressed from Equations (4) and (7).

$$
r=v_{a}\left(t_{f}-t_{i}\right)+v_{a}\left(t_{p}-t_{i}\right)-\left(Q / \pi n_{e} b\right)^{1 / 2}\left(t_{p}-t_{i}\right)^{1 / 2}
$$

The matter is more simply expressed as Equation (9).

$$
E=\left(t_{f}-t_{i}\right)+\left(t_{p}-t_{i}\right), \text { and } P=t_{p}-t_{i}
$$

Then, by combining Equations (8) and (9), and rearranging results, the advection distance and velocity can be derived as Equations (10) and (11).

$$
r=v_{a} E-\left(Q / \pi n_{e} b\right)^{1 / 2}(P)^{1 / 2}
$$

At the extraction well of the two-well test, all observation wells are set with $r=0$. Because almost all parameters have a volumetric flow rate and tracer through time, $v_{a}$ can be expressed as Equation (11).

$$
v_{a}=\left[\left(Q / \pi n_{e} b\right)^{1 / 2} P^{1 / 2}\right] / E \text { or } v_{a}^{2}=\left[\left(Q P / \pi n_{e} b\right) / E^{2}\right]
$$

Darcy's law, including an effective porosity term, can be expressed as Equation (12).

$$
v_{a}=K I / n_{e}
$$

However, Darcy's law, including AV and EP terms, can be written as Equations (11) and (12). It can be expressed as Equations (13) and (14):

$$
\begin{gathered}
v_{a}=Q P / \pi T I E^{2} \\
n_{e}=\left(\pi K T I^{2} E^{2}\right) / Q P
\end{gathered}
$$

where $v_{a}$ is the advective velocity, $n_{e}$ is the effective porosity, $P$ is the time elapsed from the start of the tracer extraction until the peak concentration arrival time at the extraction well, $E$ is the total length of time from the start of the tracer injection to the first concentration arrival time, and from the start of the tracer injection to the peak concentration arrival time (from the start of tracer injection to the first concentration arrival time (FCAT) plus $P$ ), $T$ is the transmissivity, $K$ is the hydraulic conductivity, $b$ is the saturated thickness of the aquifer, and $\mathrm{I}$ is the forced gradient resulting from the pumping conditions.

Furthermore, the single-well tracing method was modified to be applicable for the convergent flow tracer test (CFTT). The " $P$ " parameter in the two-well test is similar to the radial placement until time $t_{p}$, when pumping begins at the single-well in order to retrieve the tracer pulse. The " $E$ " parameter is similar to the time elapsed from the injection of the tracer until the centroid concentration arrival time of the solute mass is extracted (the drift time $+t$ ) in the single-well tracing test. These being such, the method may seem the same or similar to the assumptions of Leap and Kaplan. However, it has 
important differences in terms of there being two wells, a steady-state flow under a constant-rate pumping, convergent flow, dissimilar initial and boundary conditions of wells, and a forced gradient.

\subsection{Experimental Methods}

\subsubsection{Convergent Flow Tracer Test}

In CFTT, static water level was pumped from the extraction well until a steady-state flow was achieved. The forced gradient and hydraulic conductivity were determined from the zonal pumping test. The tracer injection occurred as a pulse tracer mass $(p)$, which flowed into the convergent flow field from an injection well located at a distance $(r)$ away from the pumping well, SP-05. Based on this concept, six CFTTs (SP-02 to SP-05, 03 to 05,04 to 05,06 to 05,08 to 05 , and 10 to 05 ) were performed. The experimental procedure for the zonal pumping and tracer tests (Phase 1: Constant-rate pumping, Phase 2: Pulse tracer injection, Phase 3: Tracer extraction) is shown in Figure 8.

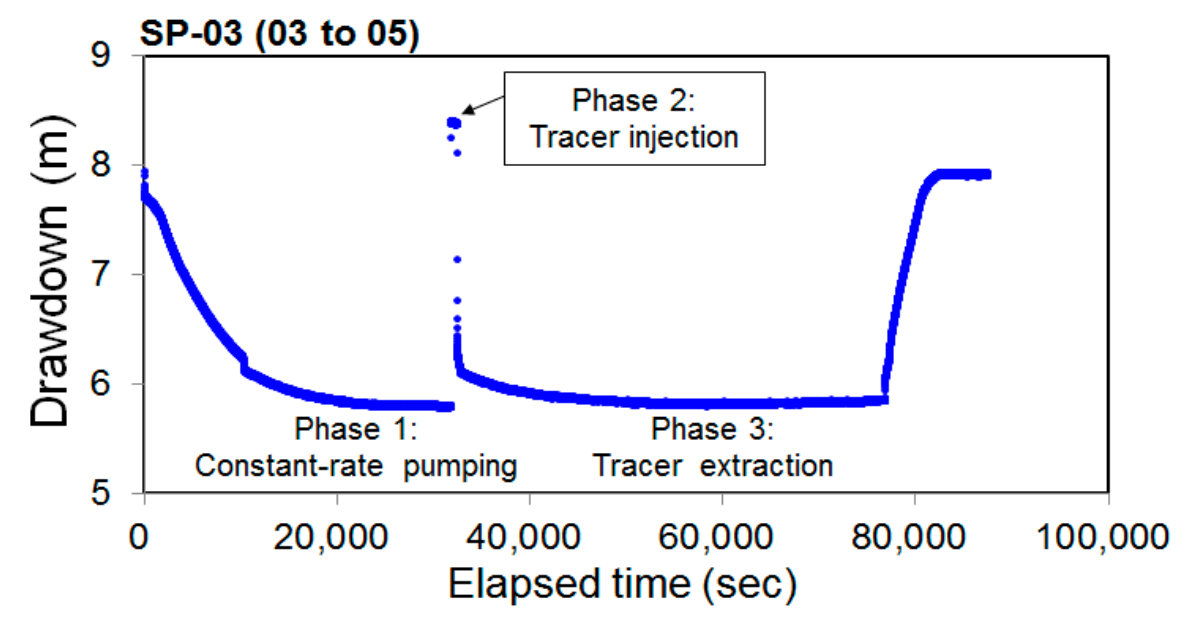

Figure 8. Drawdown curve fitting from zonal pumping test and tracer mass injection.

At the underground research tunnel, a CFTT was performed by injecting a sodium chloride solution into the injection well of the two wells. Sodium chloride was selected as the tracer because it is non-reactive and stable. The collected groundwater samples were analyzed in the field using a high-performance chlorine concentration meter. The measurement range was from 0 to $1000 \mathrm{mg} / \mathrm{L}$, and the measurement accuracy was $0.1 \mathrm{mg} / \mathrm{L}$. Through several pre-tests, an appropriate level of tracer concentration was determined to obtain an acceptable tracer recovery rate. If the tracer concentration is too low, it is difficult to detect an effective level distinguished from the background concentration, and it is difficult to obtain accurate data due to fluid separation of the high-density solution if the tracer concentration is too high. To each of the wells, SP-02, 03, 04, 06, and 10, $10 \mathrm{~L}$ of solution with a concentration of $465 \mathrm{mg} / \mathrm{L}$ was injected. Exceptionally, well SP-08 was injected for $5 \mathrm{~L}$ of solution because there is a concealed fault between wells SP-05 and SP-08, as shown in Figure 1. Due to the concealed vertical faults between boreholes SP-05 and 08, which act as flow barriers, borehole SP-08 has poor flow connectivity with the extraction borehole SP-05. Since there were a little permeable fracture with small aperture size and the natural groundwater flow is developed into the aquifer outside the test site in case of the SP-08 borehole, the tracer solution was quickly spread to the outside aquifers and disappear due to the formation of a high head gradient of approximately $2 \mathrm{~m}$, when the tracer solution of $10 \mathrm{~L}$ was injected into SP-08 borehole with NX size diameter. Thus, the tracer recovery rate was very low, when a tracer test was performed using the 5th borehole as an extraction hole. The reliable and meaningful analysis of tracer test was difficult without adequate recovery rate of tracer solution. Therefore, unlike other boreholes, the SP- 08 borehole was tested by selecting the optimal injection volume having an appropriate tracer recovery rate through several pre-tests in which the volume of injection solution was variously controlled. As a result of analyzing the concentration through in situ 
groundwater sampling, the background concentration of chloride in the test aquifer was less than $2 \mathrm{mg} / \mathrm{L}$, indicating a very low level with little impact on the tracer test results.

\subsubsection{Push-Pull Test}

The PPT is a method for analyzing solute transport by injecting the solute in a single well and then withdrawing it from the same well. As the well SP-05 is located at the center of hydraulic system, it was selected as the extraction well in CFTT to be used for PPT so as to compare the two classes of well tests. This test is comprised of a tracer injection, flush (chaser phase), and extraction phases. The flush phase included in this study was between the injection and extraction phases. In the PPT, $15 \mathrm{~L}$ of tracer (with an initial concentration of $465 \mathrm{mg} / \mathrm{L}$ ) and $5 \mathrm{~L}$ of flush (fresh water) were injected. The pumping rate and elapsed time were $1.38 \times 10^{-5} \mathrm{~m}^{3} / \mathrm{s}$ and approximately $10 \mathrm{~h}$, respectively.

In CFTT and PPT, the concentrations of the tracer solutions were detected at the extraction well, SP-05. During extraction, the tracer mass sampling was measured at intervals of $1 \mathrm{~min}$ using an automatic collector. Based on the foregoing, breakthrough curve is expressed as chloride concentration versus elapsed time.

\section{Field Results and Interpretation}

\subsection{Analysis of Breakthrough Curves in CFTT and PPT}

To ensure its reliability, we also analyzed the accumulative recovery rate of the tracer in SP wells 02 to 05,03 to 05,04 to 05,06 to 05,08 to 05 , and 10 to 05 . The results are summarized in Table 3 .

Table 3. Results of tracer accumulative recovery rate.

\begin{tabular}{lccc}
\hline Well ID & Separation Distance $(\mathbf{m})$ & Accumulative Recovery Rate of Tracer (\%) & Note \\
\hline 02 to 05 & 1.50 & 92.83 & CFTT \\
03 to 05 & 2.21 & 77.01 & CFTT \\
04 to 05 & 1.50 & 88.64 & CFTT \\
06 to 05 & 1.50 & 90.98 & CFTT \\
08 to 05 & 1.50 & 96.25 & CFTT \\
10 to 05 & 3.33 & 91.06 & CFTT \\
\hline
\end{tabular}

According to the breakthrough curves, the fractured aquifers were classified into three groups, as shown in Figure 9. Tracer responses with different fracture properties were evaluated by a close study of the three groups. The results of the six tests that were performed to evaluate the effects of the tracer responses with fracture properties are shown in Figure 9. The tracer responses in Figure 9a showed a relatively regular and symmetric shape, which indicates that the solute transport was governed by Fickian diffusion. Under a homogeneous flow field of porous media, the diffusion may have little impact on the solute transport compared to the advection-dispersion mechanism, because each pathway is relatively similar to the adjacent travel pathway. However, in fracture rock, velocity fields can be so heterogeneous that neighboring pathway can have very different flow velocities [14]. Consequently, diffusion from one pathway to another can have a significant impact on tracer transport response. Moreover, because diffusion mechanism acts very slowly compared to generally natural water velocities in permeable geologic media, the later part of the breakthrough curve (the breakthrough tailing) was considered to represent the diffusive mass exchange between fractures and the surrounding rock matrix [18]. Since most of the tracer breakthrough curves observed in this study have irregular and asymmetric shapes and long tails, this can be considered as a typical pattern of tracer transport delayed by diffusion in a fractured rock aquifer. 


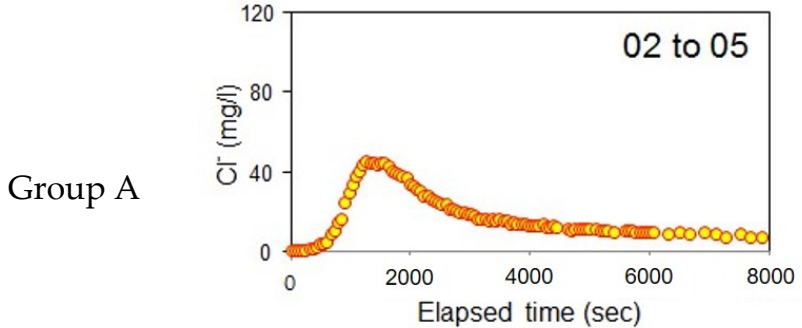

(a)

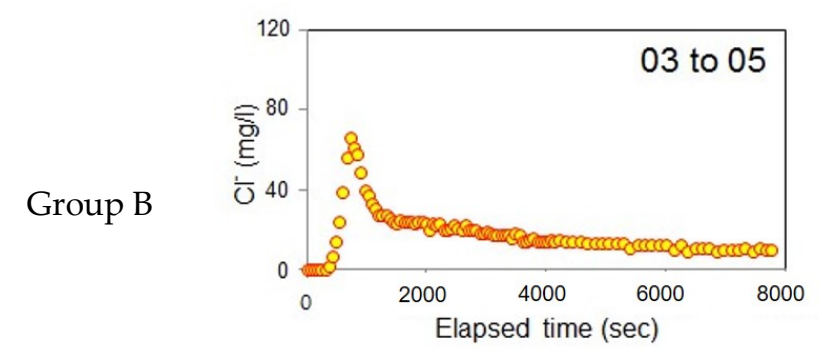

(c)

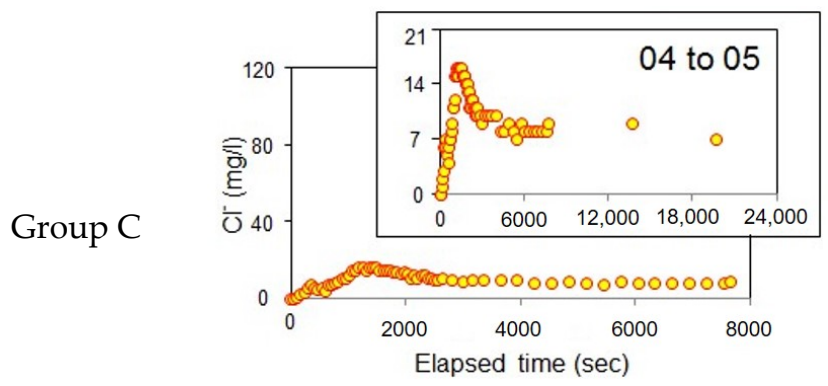

(e)

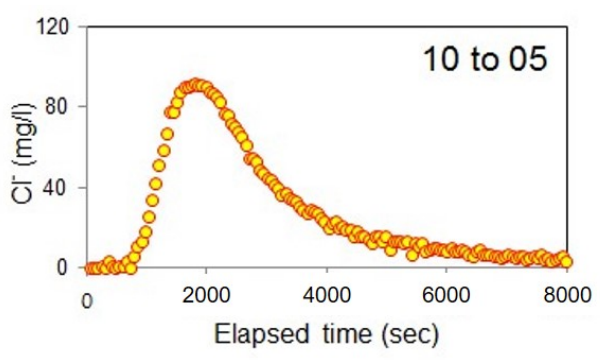

(b)

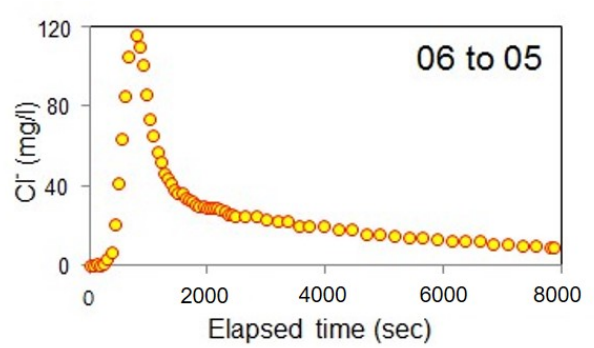

(d)

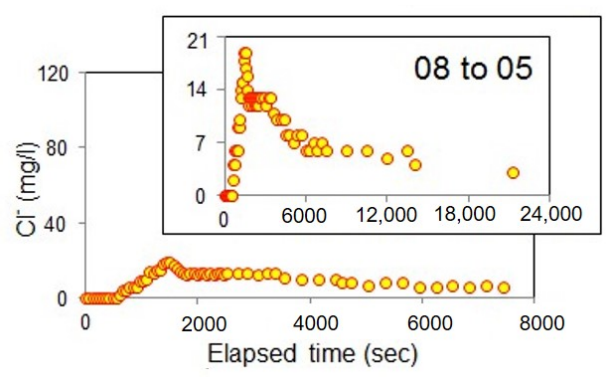

(f)

Figure 9. Classification of breakthrough curves because of heterogeneous aquifers in convergent flow tracer test (CFTTs): Group A is (a) SP-02 to 05 and (b) SP-10 to 05, Group B is (c) SP-03 to 05, (d) SP-06 to 05 , and Group C is (e) SP-04 to 05 and (f) SP-08 to 05.

The distribution of permeable fractures was governed by the sum of the products from each penetrating fracture. Thus, Group A shown in Figure 9a,b, the permeability distribution in a high fracture zone, presented tracer responses in which the fracture network did not interrupt the movement of the tracer mass. Group B shown in Figure 9c,d, exhibited breakthrough curves with more irregular and asymmetric shape, namely, fracture, dispersive structure, and matrix rock diffusion [16]. Lastly, Group C shown in Figure 9e,f showed breakthrough curves that have more irregular and asymmetric shapes, specifically, molecular diffusion and velocity gradient [19], flow reversal [20], dispersive structure, matrix rock diffusion, effects of dilution [21], and filling and remaining in the new cracks or the loss of vertical fractures due to separation of denser tracer solution [22]. The tracer particles did not move in a straight line from well to well, as shown in Figure 9b,c. Thus, the tracer mass moved along various flow paths and caused a broad range of travel time distributions. This indicated that the transport was governed by non-Fickian diffusion and that the site has heterogeneously fractured aquifers.

In this study, we presented the possibility of a close correlation between various influencing factors and tracer responses in this study. Although various influencing factors on the of the tracer response were evaluated through the analysis of the shape and size of the breakthrough curve, a more 
precise analysis about the separation of contribution degree between the influencing factors is needed to convince the direct link between the breakthrough curve and the tracer response factors.

As shown in Figure 10, the breakthrough curve of the PPT displayed a symmetric shape and shorter prolonged tailing compared with that of CFTT because the tracer solute leaving the well returned to the well along the same flow path in the PPT [23]. With respect to the accumulative recovery rate of the tracer in the PPT, well SP-05 showed an excellent recovery rate of $96.4 \%$. The breakthrough curves exhibited an asymmetric shape and prolonged tailings. When the solute transport was limited, the breakthrough curves demonstrated late-time concentration tails, as observed in our experiments.

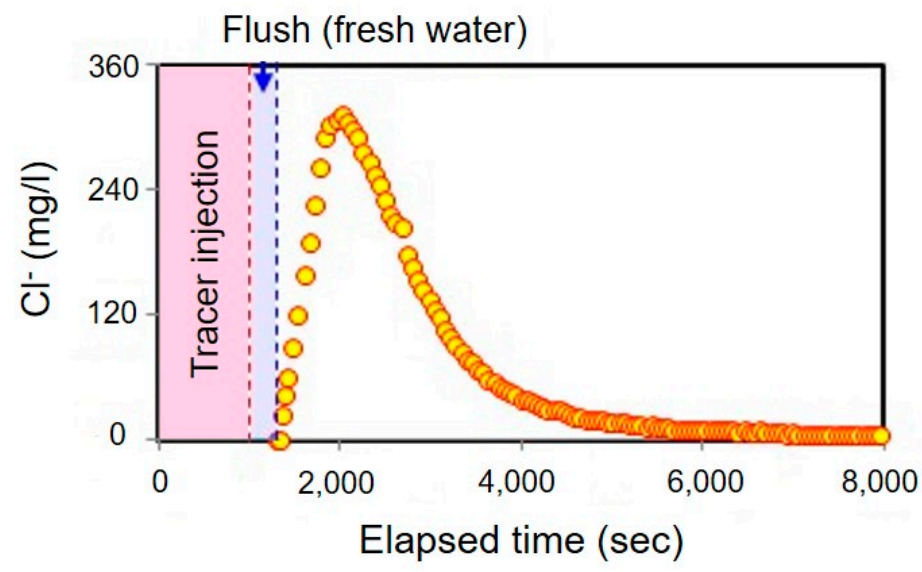

Figure 10. Breakthrough curve of PPT in SP-05.

\subsection{Advective and Effective Porosity}

In the analysis and interpretation, the travel time of the solute transport (tracer test) is an equally important factor that determines AV and EP in fractured rock mass. The advection was characterized by an axisymmetric breakthrough curve from the first to the peak arrival concentrations. In the field test, unlike the axially symmetric breakthrough curve, most of the converging flow structures did not have an axial symmetry. However, dispersion and retardation (breakthrough tailing) in the geometries (channel, fracture, and rock matrix) related to the shapes of the dispersive structures could be identified during the analysis of the flow pattern. The tracer tailing was reflected by the hydrodynamic dispersion and the matrix diffusion solute transport between the mobile water in the fractures and surrounding porous matrix [14,24]. The flow was mixed and reversed, and mixed with the rising hinge of the peak of the retarded part. Consequently, this led to a falling hinge, which was steeper than the rising hinge [13]. On the other hand, the reduction in the tracer tailing can be explained by an ideal flow path through irregular channels, fractures, and fracture zones. Thus, for the pulse injection, the peak arrival concentration time, according to the advective travel time, was based on the observation that the peak concentration $\left(C_{P}\right)$ was related to the plume's centroid, which was affected by the pore-scale heterogeneity.

The estimation for AV and EP included travel times for the FCAT, E, and $P$, all of which performed for various combinations of extraction rates, forced gradients owing to pumping and conductivity, and aquifer thickness at the well. For example, between wells SP-05 and SP-08, the peak concentration arrival time was observed to have the highest value of $570 \mathrm{~s}$. The AV and EP results for the six breakthrough curves are listed in Table 4 . 
Table 4. Results of nine tests for determining advective velocity (AV) and effective porosity (EP) by the sequence of emplacement, drift, and pumping.

\begin{tabular}{|c|c|c|c|c|c|c|c|c|}
\hline \multirow{2}{*}{\multicolumn{2}{|c|}{$\begin{array}{c}\text { Type of Tests } \\
\text { Trial Well (SP) }\end{array}$}} & \multicolumn{6}{|c|}{ Convergent Flow Tracer Tests } & \multirow{3}{*}{$\begin{array}{c}\text { Push-Pull Test } \\
\mathbf{0 5} \\
1535\end{array}$} \\
\hline & & \multirow{2}{*}{$\begin{array}{c}\mathbf{0 2} \text { to } \mathbf{0 5} \\
300\end{array}$} & \multirow{2}{*}{$\begin{array}{c}\mathbf{0 3} \text { to } \mathbf{0 5} \\
360\end{array}$} & \multirow{2}{*}{\begin{tabular}{|c|}
$\mathbf{0 4}$ to $\mathbf{0 5}$ \\
180
\end{tabular}} & \multirow{2}{*}{$\begin{array}{c}\mathbf{0 6} \text { to } \mathbf{0 5} \\
210\end{array}$} & \multirow{2}{*}{$\begin{array}{c}\mathbf{0 8} \text { to } \mathbf{0 5} \\
570\end{array}$} & \multirow{2}{*}{$\begin{array}{c}\mathbf{1 0} \text { to } \mathbf{0 5} \\
480\end{array}$} & \\
\hline & FCAT & & & & & & & \\
\hline Iravel & $\mathrm{P}$ & 1260 & 720 & 1200 & 720 & 1440 & 1800 & 1192 \\
\hline nime (s) & $\mathrm{E}^{(1)}$ & 1560 & 1080 & 1380 & 930 & 2010 & 2280 & 2637 \\
\hline \multicolumn{2}{|c|}{$v_{a}(\mathrm{~m} / \mathrm{s})$} & $2.6 \times 10^{-3}$ & $3.3 \times 10^{-3}$ & $2.2 \times 10^{-3}$ & $3.0 \times 10^{-3}$ & $1.0 \times 10^{-3}$ & $3.3 \times 10^{-3}$ & $2.4 \times 10^{-3}$ \\
\hline \multicolumn{2}{|c|}{$n_{e}$} & $2.6 \times 10^{-4}$ & $1.9 \times 10^{-4}$ & $4.3 \times 10^{-4}$ & $3.1 \times 10^{-4}$ & $1.1 \times 10^{-3}$ & $3.6 \times 10^{-4}$ & $1.3 \times 10^{-4}$ \\
\hline
\end{tabular}

(Remark) $^{(1)}$ are P plus FCAT.

In the case of the push-pull test, the effects of flow paths on heterogeneity in the fractured rock mass was significantly less than those of the two well-tracing tests, because the tracer left the well and thereafter returned to it along the same flow paths (Haggerty and Fleming, 2001). However, $\mathrm{AV}$ and EP values, using the travel time of the centroid of the tracer mass, were very similar to that estimated for the travel time of the tracer mass peak, because the shape of the breakthrough curve approximated symmetry with a short-prolonged tailing. Because the centroid of the mass was affected by the pore-scale dispersion in the single and two-well tests [25], the peak concentration arrival time, considering the center of the tracer's plume, was suitable for determining accurate average velocity and effective porosity in an asymmetric breakthrough curve observed in fractured rock aquifers.

\subsection{Comparative Analysis of Experimental Results}

For the purpose of comparison, the reliability of the results through a comparative analysis of the proposed modified method with several other methods is assessed next. Darcy's law, including an EP term, is a very common equation, which can be substituted and rearranged to yield simple algebraic expressions as Equations (15) and (16).

$$
\begin{gathered}
\bar{v}=Q /\left(A n_{e}\right) \\
Q=K A(\Delta h / \Delta L)
\end{gathered}
$$

In an aquifer where both Equations (15) and (16) are valid, the parameter $\bar{v}$ can be replaced with $\Delta L / \Delta t$, where $\Delta t$ is the centroid concentration arrival time ( $t$ ) from the tracer injection, and $\Delta L$ is the separation distance between two wells. The equations can be substituted and rearranged to yield algebraic expressions for $\mathrm{EP}$ as follows.

$$
n_{e}=t K \Delta h / \Delta L^{2}
$$

In CFTT, the pumping rate reflects the volume of water flushed through the fractures of the rock aquifer within the advective radius [26]. The EP suggested by Gaspar and Oncescu (1972) [27], whose equations are well known in CFTT, can be calculated from Equation (18). The AV in a radial flow system during the pumping period was calculated from Equation (19).

$$
\begin{gathered}
n_{e}=\frac{Q T_{i}}{\pi r^{2} b} \\
v_{a}=Q /\left(2 \pi r b n_{e}\right)
\end{gathered}
$$

In the present study, one well was pumped at a constant flow rate, $Q$, and when the flow rate was at a quasi-steady state, the tracer was injected into the other well, which is at a distance $r$ away from the pumping well. The concentration recovered from the pumping well was recorded over time. For a horizontal confined aquifer with a thickness $b, T_{i}$ was the travel time for the peak arrival concentration.

In the six two-well tests, the reliability of AV and EP was evaluated through a comparative analysis using the modified, Darcy's, and Gaspar, and Oncescu's methods, whose results are summarized and 
shown in Table 4 and Figure 11, respectively. The degree of scattering for the values of AV because of EP, using Darcy's, and Gaspar and Oncescu's methods, appear as a broad range.

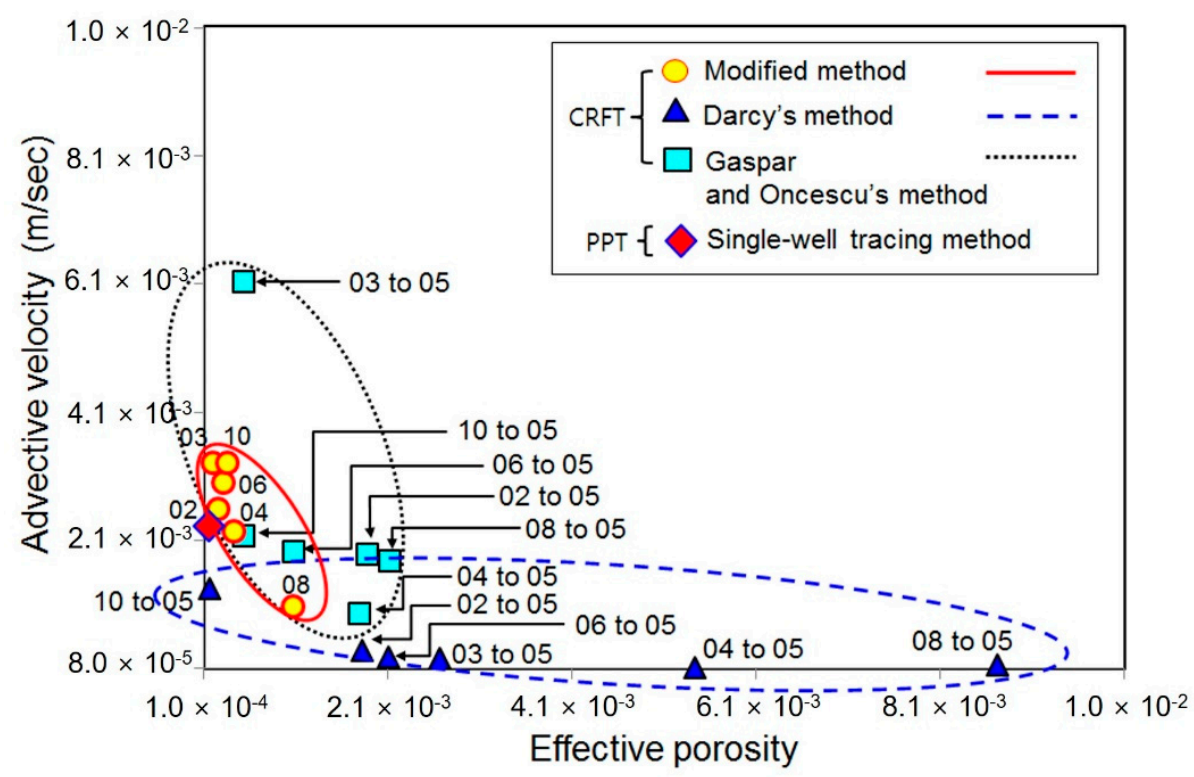

Figure 11. Comparison of Modified, Darcy's, and Gaspar-Oncescu's methods.

For the values of $\mathrm{AV}$, with the single-well method (SP-05) as the center, the rest of the values calculated from Darcy's method but exclusive of those of SP-10, were underestimated compared with those of the single-well method. Only the values for SP-03, calculated using Gaspar and Oncescu's method, were overestimated compared with those of the single-well method. For EP values, the rest of the values, calculated using Darcy's method but exclusive of those of SP-10, and values calculated using Gaspar and Onecscu's method but exclusive of SP-3, were overestimated over those of the single-well method. The values of AV and EP, using the modified method, show that the rest of the values, exclusive of those of SP-08, had similarities with the values of the single-well method. However, the modified method generated approximately similar values of AV and EP as those of the PPT method. Therefore, this method, which was modified from the single-well tracing method, can be effectively applied to two-well tests in fractured rock mass. Generally, Darcy's velocity and the average velocity are defined as the rate of change of position with respect to time. This means that the constant velocity would provide the same resultant displacement as the variable velocity, $v(t)$, over the time period $\Delta t$. Nevertheless, the interpretations using the modified method provide the most direct method for obtaining $\mathrm{AV}$ and EP.

In this study, the effective porosity is a fixed physical parameter that is an inherent property of a rock, which can be also inferred through a laboratory experiment using water saturation method by sampling a representative rock core. However, in this case, even the ratio of the unconnected or isolated void space of the rock mass is reflected in the effective porosity value. Thus, the effective porosity values obtained through a laboratory experiment is generally smaller than that obtained through a field test. Because the heterogeneous rock aquifer is composed of a complex fracture network, the geometry and ratio of the interconnected void space can be completely changed depending on the location and direction, the effective porosity obtained through field tests such as the tracer test can more realistically reflect the hydraulic characteristics of the in-situ rock aquifer. The general effective porosity in the fractured rock aquifer suggested in previous studies ranges from $1.0^{-4}$ to $1.0^{-3}$, which was similar to the effective porosity values obtained in the rock aquifer of this study site [28-30]. 


\section{Conclusions}

The modified method was derived for determining AV and EP from the results of the two classes of drifts for groundwater movement and constant volumetric flow rate for pumping during constant pumping by employing the following conditions and assumptions: First, a modified method was proposed by transforming the field test conditions and drift-and-pumpback concepts of the single-well tracing method. Second, a pulse of the conservative tracer is emplaced into two wells and the solute is allowed to drift with the forced gradient because of constant pumping, which allows constant volumetric flow for an arbitrary length of time. Third, the peak of breakthrough curve was represented by the peak concentration in an extraction well, which was associated with the plume's centroid. The total elapsed time of the two classes of drifts is taken to be the time between the beginning of the tracer injection into the well and the first concentration arrival in the extraction well. It is also the time between the beginning of the tracer arrival in the pulse image well and the peak concentration arrival in the extraction well. Finally, the pumping rate, two drift times, pumping time, AV/EP, aquifer thickness, hydraulic conductivity, and forced gradient are then used in the equation to calculate AV and EP.

Therefore, the fractured rock mass in the study area was found consistent with the structural interconnections between the testing wells evaluated by the preliminary geophysical loggings (analysis of fracture density). The fracture network estimated by the modified method was distributed uniformly in all wells, except for SP-08. The fracture network related to AV and EP could be attributed to the preferential pathways (along with permeability fracture) because of the degree of fracture connectivity. The selection of the peak of the tracer mass suitable for the heterogeneity of the relevant aquifers is very important for an accurate analysis of the tracer test in a two-well test. The two simultaneous equations for $\mathrm{AV}$ and $\mathrm{EP}$, using the modified method, can reduce uncertainty and characterize the solute transport in the fractured rock mass.

Author Contributions: B.-W.K. designed and initiated the research, and made the modified convergent flow tracing method. B.-W.K. and H.L. analyzed the experimental results, prepared the original draft, and reviewed and edited the final draft. All authors have read and agreed to the published version of the manuscript.

Funding: This research was supported by Korea Atomic Energy Research Institute (KAERI) through the Korean Nuclear Energy R\&D program, funded by the Ministry of Science and ICT of South Korea. And this study was also supported by Korea Environment Industry \& Technology Institute (KEIT) through Demand Responsive Water Supply Service Program, funded by Korea Ministry of Environment (MOE)(146517).

Acknowledgments: This paper is a work revised and supplemented from the internal technical report (KAERI/TR-6342/2016) produced by the research project on KURT geological environment characteristic evaluation technology development. We are grateful to the researchers in the Radioactive Waste Disposal Research Division of KAERI who helped improve the quality of the paper.

Conflicts of Interest: The authors declare no conflict of interest

\section{References}

1. Worthington, S.R.H. Diagnostic tests for conceptualizing transport in bedrock aquifers. J. Hydrol. 2015, 529, 365-372. [CrossRef]

2. Brkić, Ž.; Mladen Kuhta, M.; Hunjak, T. Groundwater flow mechanism in the well-developed karst aquifer system in the western Croatia: Insights from spring discharge and water isotopes. CATENA 2018, 161, 14-26. [CrossRef]

3. Darcy, H. Les Fontaines Publiques de la Ville de Dijon; Saraswati Press: Paris, France, 1856; p. 647.

4. Leap, D.I.; Kaplan, P.G.A. Single-well tracing method for estimating regional advective velocity in a confined aquifer: Theory and preliminary laboratory verification. Water Resour. Res. 1988, 24, 993-998. [CrossRef]

5. Hall, S.H.; Luttrell, S.P.; Cronin, W.E. A method for Estimating Effective Porosity and Ground-Water Velocity. Ground Water 1991, 29, 171-174. [CrossRef]

6. Stephens, D.B.; Hsu, K.-C.; Prieksat, M.A.; Ankeny, M.D.; Blandford, N.; Roth, T.L.; Kelsey, J.A.; Whitworth, J.R. A comparison of estimated and calculated effective porosity. Hydrogeol. J. 1998, 6, 156-165. [CrossRef] 
7. Fernàndez-Garcia, D.; Sànchez-Vila, X.; Illangasekare, T.H. Convergent-flow tracer tests in heterogeneous media: Combined experimental-numerical analysis for determination of equivalent transport parameters. J. Contam. Hydrol. 2002, 57, 129-145.

8. Neuman, S.P. On the tensorial nature of advective porosity. Adv. Water Resour. 2005, 28, 149-159. [CrossRef]

9. Lee, S.Y.; Bail, M.-H.; Cho, W.J.; Hahn, P.-S. Rock weathering and geochemical characteristics in the KURT. J. Korean Radioact. Waste Soc. 2006, 4, 321-328.

10. Kim, G.Y.; Koh, Y.K.; Bae, D.S.; Kim, C.S. Mineralogical characteristics of fracture-filling minerals from the deep borehole in the Yuseong area for the radioactive waste disposal project. J. Miner. Soc. Korea 2004, 17, 99-114.

11. Barker, J.A. A generalized radial flow model for hydraulic tests in fractured rock. Water Resour. Res. 1988, 24, 1796-1804. [CrossRef]

12. Liu, Y.; Kitanidis, P.K. Applicability of the Dual-domain Model to Nonaggregated Porous Media. Ground Water 2012, 50, 927-934. [CrossRef] [PubMed]

13. Hauns, M.; Jeannin, P.-Y.; Atteia, O. Dispersion, retardation and scale effect in tracer breakthrough curves in karst conduits. J. Hydrol. 2001, 241, 177-193. [CrossRef]

14. Becker, M.W.; Shapiro, A.M. Tracer transport in fractured crystalline rock: Evidence of nondiffusive breakthrough tailing. Water Resour. Res. 2000, 36, 1677-1686. [CrossRef]

15. Suzuki, A.; Makita, H.; Niibori, Y.; Fomin, S.A.; Chugunov, V.A.; Hashida, T. Characterization of tracer responses using fractional derivative-based mathematical model and its application to prediction of mass transport in fractured reservoirs. GRC Trans. 2012, 36, 1391-1396.

16. Zlotnik, V.A.; Logan, J.D. Boundary conditions for convergent radial tracer tests and effect of well bore mixing volume. Water Resour. Res. 1996, 32, 2323-2328. [CrossRef]

17. Hoehn, E.; Roberts, P.V. Advection-Dispersion Interpretation of Tracer Observations in an Aquifer. Ground Water 1982, 20, 457-465. [CrossRef]

18. Maloszewski, P.; Zuber, A. Tracer experiments in fractured rocks-Matrix diffusion and the validity of models. Water Resour. Res. 1993, 29, 2723-2735. [CrossRef]

19. Taylor, G.I. Dispersion of soluble matter in solvent flowing slowly through a tube. P. Roy. Soc. A-Math. Phy. 1953, A219, 186-203.

20. John, A.K.; Lake, L.W.; Bryant, S.L.; Jennings, J.W. Investigation of Field Scale Dispersion. Soc. Petrol. Eng. 2008, 1-19. [CrossRef]

21. Rossier, Y.; Kiraly, L. Effect de la dilution sur la dé determination des dispervisites par interprétation des essais de tracage dans les aquifers. Bull. Du Centre D'hydrogéol. De Neuchâtel 1992, 11, 1-15.

22. Liedtke, L.; Götschenberg, A.; Jobmann, M.; Siemering, W. Observations of Tracer Behaviour in Micro-Fissures and Fractures as well as Numerical Transport were Made in Grimsel Hard Rock Laboratory: BOHRLOCHKRANZVERSUCH Experimentelle und Numerische Untersuchungen zum Stoff Transport in Geklüftetem Fels; Technischer Bericht 94-02; Nationale Genossenschaft für die Lagerung Radioaktiver Abfälle, Bundesanstalt tür Geowissenschaften und Rohstoffe: Hannover, Germany, 1994; p. 197.

23. Haggerty, R.; Fleming, S.W. Tracer tests in a fractured dolomite: 2. Analysis of mass transfer in single-well injection-withdrawal test. Water Resour. Res. 2001, 37, 1129-1142. [CrossRef]

24. Callahan, T.J.; Reimus, P.W. Using multiple experimental methods to determine fracture/matrix interactions and dispersion of nonreactive solutes in saturated volcanic tuff. Water Resour. Res. 2000, 36, 3547-3558. [CrossRef]

25. Rubin, Y.; Ezzedine, S. The travel times of solutes at the Cape Cod Tracer Experiment: Data analysis, modeling, and structural parameters inference. Water Resour. Res. 1997, 33, 1537-1547. [CrossRef]

26. Niemann, W.L.; Rovey, C.W., II. Comparison of Hydraulic Conductivity Values Obtained from Aquifer Pumping Tests and Conservative Tracer Tests. Ground Water Monit. Remed. 2000, 20, 122-128. [CrossRef]

27. Gaspar, E.; Oncescu, M. Radioactive Tracers in Hydrology; Elsevier: New York, NY, USA, 1972.

28. Domenico, P.A.; Schwartz, F.W. Physical and Chemical Hydrogeology; John Wiley \& Sons, Inc.: Hoboken, NJ, USA, 1998; p. 506.

29. Kang, D.H.; Chung, S.Y.; Kim, B.W. The characteristics of hydrodynamic dispersion in a horizontally heterogeneous fractured rock through single well injection withdrawal tracer tests. J. Soil Groundw. Environ. 2006, 11, 53-60. 
30. Kim, B.-W.; Koh, Y.-K.; Park, K.-W.; Ji, S.-H.; Ryu, J.-H.; Jeong, H.Y. A Modified Two-Well Tracing Method for Advective Velocity and Effective Porosity from Single-Well Tracing Method; KAERI Report No. KAERI/TR-6342/2016, Technical Report; KAERI: Daejeon, Korea, 2016; pp. 1-52.

Publisher's Note: MDPI stays neutral with regard to jurisdictional claims in published maps and institutional affiliations.

(C) 2020 by the authors. Licensee MDPI, Basel, Switzerland. This article is an open access article distributed under the terms and conditions of the Creative Commons Attribution (CC BY) license (http://creativecommons.org/licenses/by/4.0/). 